\title{
Morfologia do esôfago de Bradypus variegatus (Schinz, 1825)
}

\author{
Ellen Yasmin Eguchi Mesquita 1,2* \\ Paola Cardias Soares ${ }^{1}$ \\ Luise Ratis Mello ${ }^{1}$ \\ Ana Rita Lima ${ }^{1}$ \\ Elane Guerreiro Giese ${ }^{1}$ \\ Érika Branco ${ }^{1}$ \\ ${ }^{1}$ Universidade Federal Rural da Amazônia, Instituto de Saúde e Produção Animal \\ Laboratório de Morfologia Animal \\ Avenida Presidente Tancredo Neves, 2501, Terra Firme, CEP 66.077-830, Belém - PA, Brasil \\ ${ }^{2}$ Universidade da Amazônia, Belém - PA, Brasil \\ * Autor para correspondência \\ elleneguchi@yahoo.com.br
}

Submetido em 18/11/2018

Aceito para publicação em 17/05/2019

\section{Resumo}

Bradypus variegatus, vulgarmente conhecida como preguiça comum, pertence a um grupo individualizado de mamíferos, com peculiaridades morfológicas e biológicas já descritas, porém, pouco se sabe sobre questões estruturais do seu trato digestório, incluindo a morfologia do esôfago. Diferindo dos mamíferos em geral quanto ao trajeto completo do órgão, o esfíncter esofágico cranial localiza-se dorsalmente à laringe, desviando à esquerda da traqueia, mantendo-se adjacente a ela, ainda no antímero esquerdo, ao longo da porção cervical. No tórax, seguiu pelo mediastino, atravessou transversalmente o diafragma através do hiato esofágico, alcançando o estômago. Histologicamente, apresentou o mesmo padrão tecidual ao longo das três porções, destacando-se a presença de três camadas musculares, adensando na porção torácica, e na adventícia cercada pela cadeia nervosa simpática, adjacente à região cárdica. Essas características histológicas conferem ao esôfago dessa espécie arquitetura peculiar, que pode explicar o comportamento de deglutição destes indivíduos frente aos seus hábitos posturais.

Palavras-chave: Anatomia; Aparelho Digestório; Preguiça; Xenarthras

\section{Abstract}

Morphological characteristics of the esophagus of Bradypus variegatus (Schinz, 1825). Bradypus variegatus, commonly known as the brown-throated sloth, belongs to a distinct group of mammals with some morphological and biological peculiarities that have already been described. However, little is known about the structure of its digestive tract, including the morphology of the esophagus. Unlike mammals in general, the esophagus sphincter of $B$. variegatus starts dorsally to the larynx and diverts to the left of the trachea, remaining adjacent to it, in the left antimer along the entire cervical portion. In the thorax, it follows the mediastinum and crosses the diaphragm through the esophageal hiatus before reaching the stomach. Histologically, it exhibits the same tissue pattern throughout the three portions, including three muscular layers, thickening in the thoracic 
portion, and adventitia surrounded by the sympathetic nerve chain, adjacent to the cardiac region. These histological characteristics show that the esophagus architecture of this species is peculiar, which may explain the swallowing behavior of this animal in relation to its postural habits.

Key words: Anatomy; Digestive Tract; Sloth; Xenarthras

\section{Introdução}

As funções primárias do tubo digestório são a digestão e a absorção de nutrientes, essenciais aos processos metabólicos dos animais, além de revelar hábitos alimentares gerais, sendo útil para a sistemática. Os nutrientes digeridos são absorvidos pelo epitélio e transferidos para a circulação (HILDEBRAND; GOSLOW, 2006).

As preguiças estão entre as poucas espécies de mamíferos arborícolas com hábito alimentar estritamente folívoro (CORK; FOLEY, 1991), conhecido pelos movimentos lentos e baixa taxa metabólica, habitando florestas e alimentando-se de folhas, ramos e brotos de várias plantas, frequentemente da família Moraceae (CHIARELLO, 2008), Cecropiaceae e Clethraceae (URBANI; BOSQUE, 2007), sendo que as folhas representam 94\% dos itens consumidos (QUEIROZ, 1995).

As adaptações para a dieta folívora arborícola de preguiças são evidentes logo na mastigação. Devido às especializações para trituração dos alimentos fibrosos, as preguiças dispõem de músculos faciais reduzidos em número e complexidade em comparação com os músculos de carnívoros (NAPLES, 1985). Em consonância, o comportamento acrobático e a lateralidade realizada por estes Xenarthras fazem deles um grupo diferenciado, inclusive no momento da alimentação (CONSENTINO, 2004; PINHEIRO, 2006).

Para compreender a dieta de animais selvagens é importante conhecer a morfologia do trato digestório, porém, há escassez literária quanto ao tema, o que impede a compreensão dos processos digestivos e a alimentação adequada para cada espécie (PINHEIRO et al., 2014). É pacificado que o tubo digestório é estruturalmente variável nos animais vertebrados, inclusive entre espécies do mesmo gênero (ZAMITH, 1952). A mastigação, o transporte de alimento e a deglutição dos mamíferos também ocorrem de maneira diferente dos outros vertebrados (PARSONS; ROMER, 1985), uma vez que as diferenças anatômicas entre as espécies podem refletir nas adaptações filogenéticas de diversas dietas alimentares (FOWLER, 1998).

$\mathrm{Na}$ anatomia do tubo digestório, a primeira porção tubular percorrida pelo bolo alimentar é o esôfago, o qual tem por função conduzir o alimento da faringe ao estômago (DYCE et al., 2010), possuindo três porções (cervical, torácica e abdominal). Histologicamente, em alguns animais domésticos já descritos, é composto por quatro camadas: mucosa, submucosa, muscular e adventícia/serosa (SAMUELSON, 2007).

Topograficamente, o esôfago se apresenta nos herbívoros como um tubo relativamente estreito que começa dorsalmente na cartilagem cricoide da laringe e acompanha a traqueia ao longo do pescoço, se inclinando inicialmente à esquerda e retomando a posição mediana dorsal. Ao atingir a região torácica, apresenta desvio á esquerda do arco aórtico e reassume o antímero esquerdo na porção abdominal no cárdia estomacal. $\mathrm{O}$ bolo alimentar segue morfologicamente a arquitetura do tubo, passando por etapas de lubrificação, até alcançar o estômago (DYCE et al., 2010).

Histologicamente, o esôfago de alguns animais apresenta configurações distintas de acordo com o hábito alimentar, podendo ser composto por epitélio pavimentoso estratificado, com ausência de queratina e sustentado por lâmina própria (SAMUELSON, 2007), ou mesmo ser queratinizado, ou seja, dotado de camada de queratina na superfície do epitélio, provavelmente relacionada à dieta mais fibrosa (NASCIUTTI et al., 2016). Além do epitélio da lâmina própria, existe uma delicada camada muscular lisa dotada de feixes orientados longitudinalmente, a muscular da mucosa, que delimita a mucosa da submucosa, adjacente à camada muscular lisa dupla, e mais externamente segue 
a adventícia, constituída de tecido conjuntivo frouxo (STINSON; CALHOUN, 1982; LANGER, 2003).

Diante do exposto, objetivou-se investigar as características morfológicas do esôfago de $B$. variegatus, a fim de subsidiar o entendimento de sua digestão, bem como de seu comportamento alimentar, e com isso auxiliar na preservação da espécie.

\section{Material e Métodos}

Foram utilizados sete animais adultos (quatro fêmeas e três machos), provenientes do Bosque Rodrigues Alves Jardim Botânico da Amazônia, município de Belém, Estado do Pará, Brasil (SISBIO № 49221), que viviam em regime semi-cativo e foram a óbito por causas naturais, não correlatas ao aparelho digestório. Dos sete animais estudados, um grupo com cinco indivíduos (três fêmeas e dois machos) foi imediatamente congelado, por período médio de sete dias, e um grupo com dois animais (uma fêmea e um macho) foi utilizado em condição de óbito recente. Todos os animais foram encaminhados ao Laboratório de Pesquisa Morfológica Animal (LaPMA), da Universidade Federal Rural da Amazônia (UFRA-PA).

Inicialmente, os animais congelados foram descongelados em água corrente, por período de aproximadamente $6 \mathrm{~h}$ e, em seguida, com auxílio de material básico de dissecação, realizou-se incisão longitudinal na região mentoniana, estendendo-se pela linha mediana ventral do pescoço, do tórax, do abdome, até a região pré-umbilical, rebatendo-se a cútis, musculatura e o esterno, o qual foi incisado nas articulações costocondrais, seguido de exposição do esôfago, até seu ponto de desembocadura no estômago. Esta foi a mesma metodologia de abordagem utilizada nos animais com óbito recente.

Após fotodocumentação para registro da topografia do esôfago, o órgão foi removido e foram fixadas amostras de $2 \mathrm{~cm}$ das porções cervical, torácica e abdominal, em solução aquosa de formaldeído a 10\% tamponado, para avalição pela microscopia de luz, seguindo protocolo de rotina histológica de Hematoxilina-Eosina e Tricrômico de Gomori (TOLOSA et al., 2003).
As nomenclaturas adotadas seguiram os padrões da Nomina Anatomica Veterinaria (INTERNATIONAL COMMITTEE ON VETERINARY GROSS ANATOMICAL NOMENCLATURE, 2017) e da Nomina Histologica Veterinária (INTERNATIONAL COMMITTEE ON VETERINARY HISTOLOGICAL NOMENCLATURE, 2017).

\section{Resultados}

Topograficamente, o esôfago iniciou dorsal à laringe e imediatamente desviou à esquerda da traqueia, mantendo-se adjacente a ela, ainda no antímero esquerdo ao longo de toda a extensão cervical. No tórax, o esôfago foi identificado no mediastino e, em seguida atravessou transversalmente o diafragma através do hiato esofágico, alcançando o estômago à esquerda do plano mediano (Figura 1).

Macroscopicamente, o esôfago de B. variegatus apresentou mucosa pregueada em toda extensão, com uma estrutura que se projeta em direção ao lúmen do órgão na porção cárdica do estômago, semelhante a uma válvula ou esfíncter proeminente.

Histologicamente, o esôfago seguiu o mesmo padrão tecidual ao longo das três porções (cervical, torácica e abdominal) com pequenas modificações (Figura 2). A mucosa do órgão constituía-se por tecido pavimentoso queratinizado estratificado, composto de estrato córneo sem padrão de estratificação, com formações de pregas suportadas somente por queratina, sucedido pela lâmina própria.

A submucosa de tecido conjuntivo frouxo se mostrou sem glândulas, ausência de muscular da mucosa, com a túnica muscular marcante contendo três camadas (longitudinal, transversal e longitudinal), e adensamento da musculatura na porção torácica. Toda a extensão do órgão mostrou-se composta por musculatura estriada esquelética, com núcleos periféricos, sendo as células multinucleadas, e adventícia formada por tecido conjuntivo frouxo, com a cadeia nervosa simpática circunscrevendo o órgão próximo à região cárdica. 
FIGURA 1: A e B: Anatomia topográfica in situ do esôfago de preguiças da espécie Bradypus variegatus. A) 1 - Estômago; 2 - Esôfago abdominal; 3 - Esôfago cervical; 4 - Traqueia (Barra de escala: $2 \mathrm{~cm}$ ). B) Trajetória completa do esôfago após remoção do aparelho cardiorrespiratório (Barra de escala: $2 \mathrm{~cm}$ ). C) Válvula cardioesofágica 1 - Estômago; 2 - Esfíncter gástrico (Barra de escala: $1 \mathrm{~cm})$.
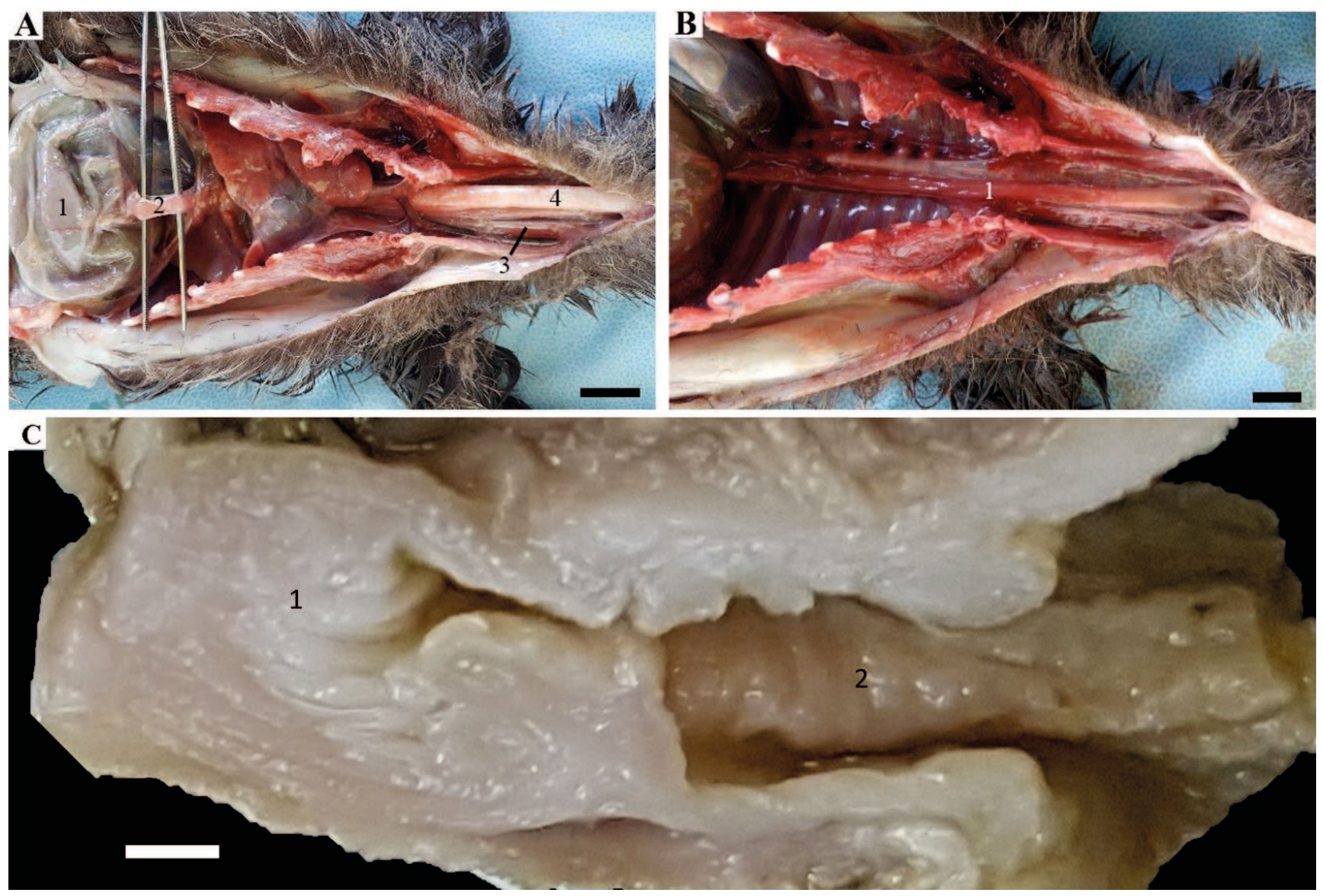
FIGURA 2: Fotomicrografia do esôfago de preguiça da espécie Bradypus variegatus. A) Corte transversal do esôfago, da porção abdominal indicando mucosa pregueada (seta); B) Corte longitudinal do esôfago, porção abdominal com o padrão das camadas do órgão (mucosa com as dobras de queratina - seta azul), túnica muscular com as três camadas, Transversal (1), longitudinal (2) e transversal (3), e plexo nervoso autônomo na serosa (seta preta); C) Camada muscular apresentando estrias (seta preta) e núcleos periféricos (setas laranja e verde) caracterizando o tecido muscular esquelético; D) Criptas de tecido epitelial na mucosa invadindo a luz do órgão (seta azul). Barras de escala e coloração: A: $500 \mu \mathrm{m}$, hematoxilina-eosina; B: $100 \mu \mathrm{m}$, hematoxilina-eosina; C: $20 \mu \mathrm{m}$, hematoxilina-eosina; D: $100 \mu \mathrm{m}$, Tricrômico de Gomori.
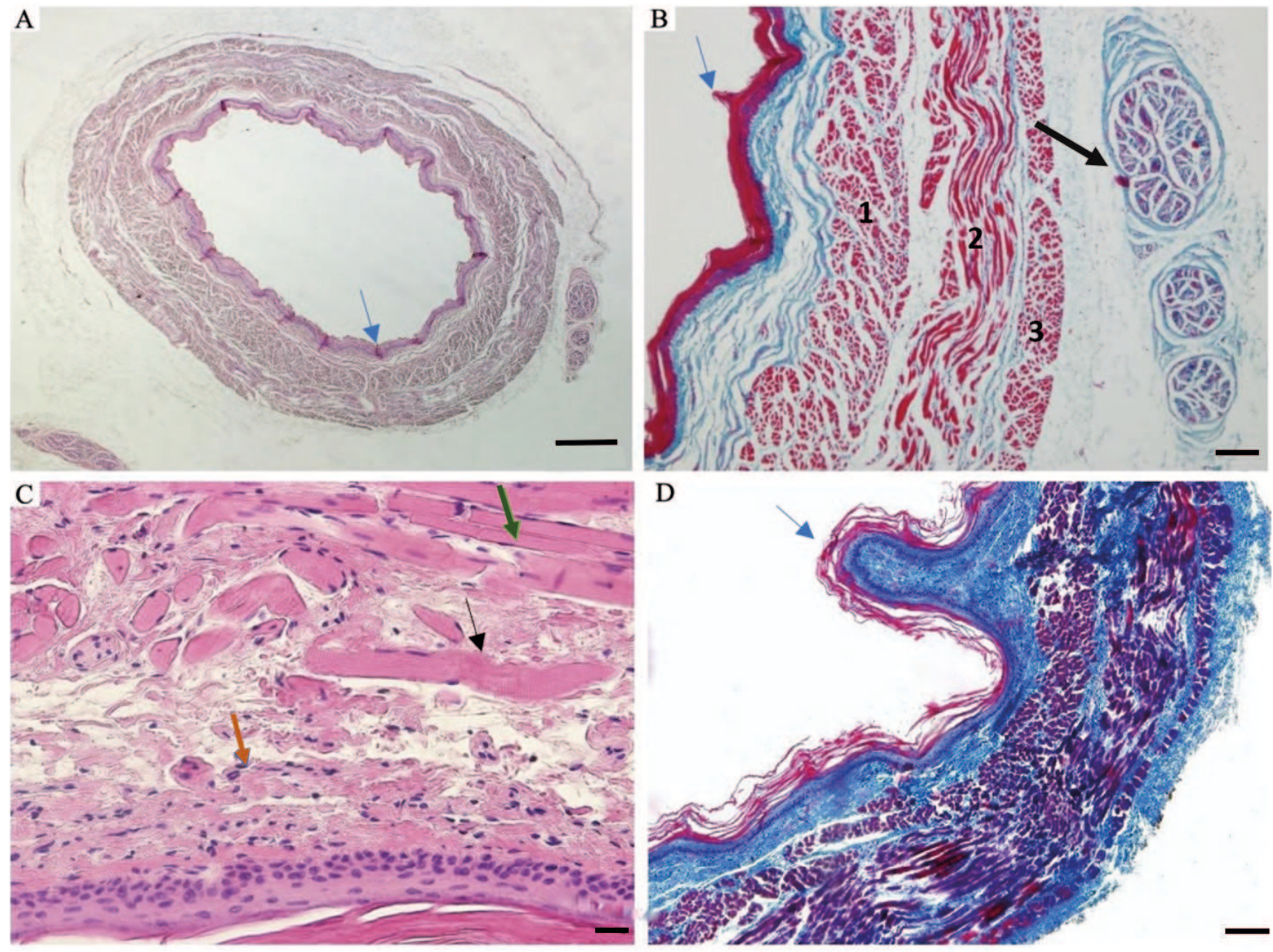

A porção do esfíncter, ou válvula cárdica, apresentou também mucosa de tecido plano queratinizado, semelhante a toda extensão do órgão, composto de estrato córneo sem padrão de estratificação, com formações de pregas suportadas somente por queratina, sucedido pela lâmina própria e submucosa de tecido conjuntivo frouxo, ausência de glândulas e muscular da mucosa (Figura 3). 
FIGURA 3: Fotomicrografia da válvula cardioesofágica de preguiça da espécie Bradypus variegatus. A) Válvula cardioesofágica (V) com a projeção para o lúmen do órgão (L); B) Padrão misto muscular entremeado, composto por musculatura lisa (seta preta) e musculatura estriada esquelética (seta amarela). Barras de escala e coloração: A: $100 \mu \mathrm{m}$, Tricrômico de Gomori; B: $20 \mu \mathrm{m}$, Tricrômico de Gomori.

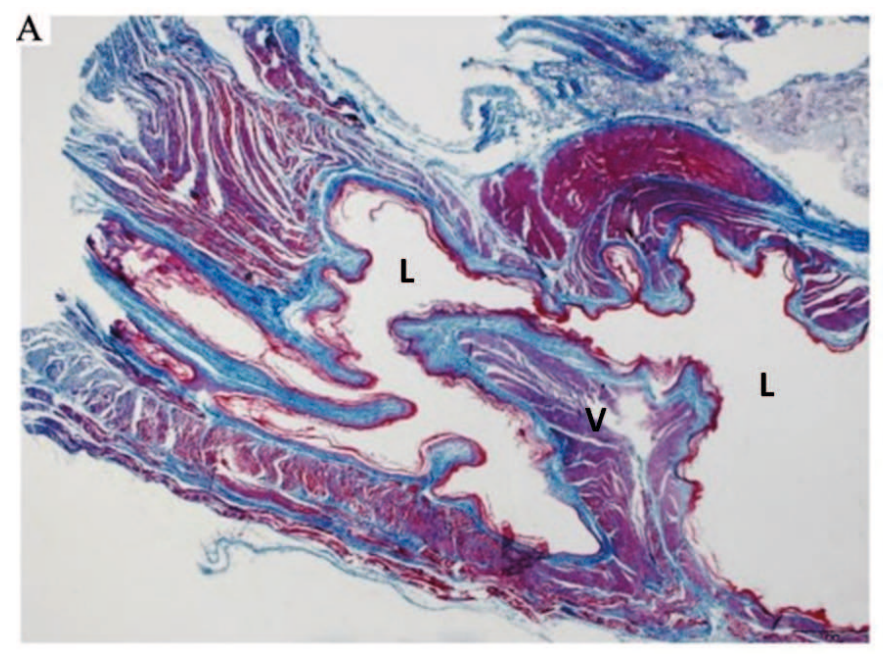

A camada muscular, composta por três feixes em oposição, exibiu um padrão misto, composto tanto por musculatura lisa quanto por músculo estriado esquelético, que se entrecruzam na mesma porção, e a serosa, já bem caracterizada, composta por tecido conjuntivo frouxo e células epiteliais pavimentosas.

\section{Discussão}

A disposição do esôfago de B. variegatus, situado exclusivamente no antímero esquerdo do pescoço, apresentando o trajeto retilíneo e ausência de flexura, difere da literatura já descrita tanto em carnívoros quanto em herbívoros domésticos (GETTY, 1986; MURRAY, 1998; DYCE et al., 2010), porém, se assemelha à descrita por Dias et al. (2015), em tamanduás-mirins. Essa condição, em conjunto ao comportamento alimentar suspenso com os membros pélvicos acima e a cabeça em plano inferior, supostamente esclarece a necessidade de maior controle de movimento do bolo alimentar. A presença de flexuras usualmente descrita em animais domésticos dificultaria esse retorno, o que não é o caso em preguiças, uma vez que as flexuras se justificam pela presença de uma densa válvula cardioesofágica, que tende a evitar o processo de refluxo.

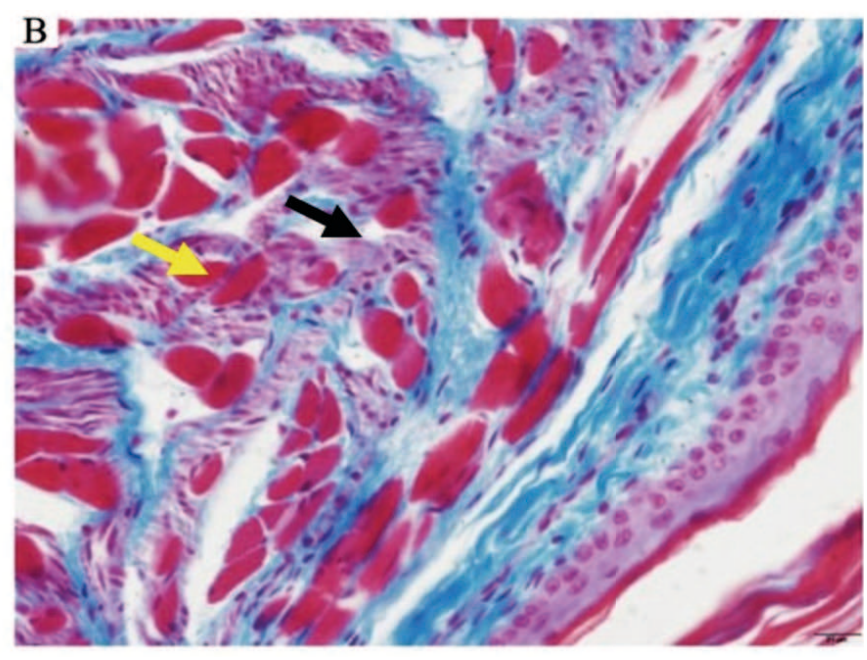

A microscopia do esôfago confirma que este apresenta características próprias, já que a mucosa revela pregas dispostas pela superfície interna, diferentemente dos animais domésticos, em que as pregas desaparecem na porção abdominal (GENESER, 2003; GARTNER; HIATT, 2007). Além disso, há ausência de glândulas esofágicas, o que, com as características anatômicas, confirma que o órgão possivelmente apresenta funcionalidade apenas mecânica, como acontece com a tartaruga verde (Chelonia mydas), para a qual os autores sugerem a mesma função (MAGALHÃES et al., 2010).

A ausência de lubrificação com base no movimento de deglutição antigravitacional, reforçada pela presença da musculatura esquelética, leva a crer que existe algum controle do bolo alimentar, e a lubrificação, possivelmente, deve ocorrer pela salivação do animal.

A literatura aponta também que ruminantes e cães possuem igualmente a túnica muscular composta de musculatura esquelética, porém, formada por dois feixes musculares (SAMUELSON, 2007), bem como a descrição morfológica do esôfago de capivara, cuja camada muscular também é constituída por duas camadas de músculo estriado esquelético desenvolvidas ao longo do órgão, influenciando no transporte de partículas remanescentes após a deglutição (VELÁSQUEZ et al., 2016). 
A espécie $B$. variegatus apresenta três camadas musculares, o que possivelmente leva ao controle dos movimentos esofágicos de regurgitação ainda mais preciso quando comparado aos dos ruminantes que utilizam esse domínio muscular para o retorno alimentar no processo de ruminação (BANKS, 1992).

Ao final do trajeto alimentar até o estômago, B. variegatus apresenta uma válvula cárdica, presumidamente controlada pelo aparelho nervoso autônomo a fim de evitar o refluxo, já que a anatomia retilínea favoreceria o evento. Em caninos, a finalidade da válvula cárdica já é descrita e consiste em evitar a regurgitação, já que, à medida que o bolo alimentar transita inicialmente pelo esôfago, ocorre a diminuição da pressão do esfíncter esofágico caudal, relaxando-o e permitindo a passagem do alimento ao estômago. Após a passagem do bolo, o esfíncter se contrai e cria uma zona de alta pressão. A contração evita o refluxo do conteúdo gástrico dentro da porção distal do esôfago (HOFFER et al., 1979; BANKS, 1992).

Possivelmente, B. variegatus segue o padrão semelhante dos animais domésticos nesse aspecto, já que a histologia também mostra a composição mista de tecido muscular liso e esquelético e o enlace do plexo nervoso autônomo. No entanto, a porção cárdica difere no que diz respeito às glândulas.

Em animais com o estômago monocavitário, o esfíncter cárdico também possui glândulas secretoras de muco (glândulas tubulares ramificadas mucosas, cuja secreção protege a parede do esôfago de um refluxo de suco gástrico) (GENESER, 2003; SAMUELSON, 2007; ROSS; PAWLINA, 2012). Já em B. variegatus, essas glândulas estão ausentes, reiterando a função mecânica exclusiva do órgão (FRAPE, 2004).

Por fim, conclui-se que a configuração única retilínea do tubo esofágico, associada à densa musculatura, confere a esse órgão características singulares quando aliadas à complexidade de comportamentos posturais pré e pós-ingesta da espécie.

\section{Referências}

BANKS, B. I. Aparelho digestivo. I - Canal alimentar. In: BANKS, B. I. (Ed.). Histologia veterinária aplicada. 2. ed. São Paulo: Manole, 1992. p. 437-450.

CHIARELLO, A. G. Sloth ecology: an overview of field studies. In: VIZCAÍNO, S. F.; LOUGHRY, W. J (Ed.). The biology of the Xenarthra. Gainesville: University Press of Florida, 2008. p. 638671.

CONSENTINO, L. N. Aspectos do comportamento da preguiçacomum, Bradypus variegatus (Xenarthra, Bradipodidae) em uma área de semi-cativeiro no município de Valença - Rio de Janeiro. 2004. 38 f. Dissertação (Mestrado em Biologia Animal) - Universidade Federal Rural do Rio de Janeiro, Seropédica. 2004.

CORK, S. J.; FOLEY, W. J. Digestive and metabolic strategies of arboreal mammalian folivores in relation to chemical defenses in temperate and tropical forests. In: PALO, R. T.; ROBBINS, C. T. (Ed.). Plants defenses against mammalian herbivory. Florida: CRC Press, 1991. p. 133-166.

DIAS, G. F.; SIQUEIRA, R. A. S.; FIRMINO, M. O.; GUERRA, R. R. Anatomia topográfica do aparelho digestivo de tamanduá mirim (Tamadua tetradactyla, Linnaeus 1758) In: CONGRESSO DA SOCIEDADE DE ZOOLÓGICOS E AQUÁRIOS DO BRASIL, 39, 2015, Foz do Iguaçu. Resumos... Foz do Iguaçu: SZB, 2015. Versão eletrônica.

DYCE, K. M.; SACK, W. O.; WENSING, C. J. G. Tratado de anatomia veterinária. 3 ed. São Paulo: Saunders Elsevier, 2010. $813 \mathrm{p}$.

FOWLER, M. E. Medicine and surgery of South American camelids: llama, alpaca, vicuna, guanaco. Ames: Iowa State University Press, 1998. 391 p.

FRAPE, D. Equine nutrition and feeding. 3. ed. Oxford: Blackwell Publishing, 2004. 650 p.

GARTNER, L. P.; HIATT, J. L. Tratado de histologia em cores. 3 ed. Rio de Janeiro: Elsevier, 2007. 373 p.

GENESER, F. Histologia com bases moleculares. 3. ed. Buenos Aires: Médica Panamericana/ Rio de Janeiro: Guanabara Koogan, 2003. 125 p.

GETTY, R. Anatomia dos animais domésticos. Vol. 2. 5. ed. Rio de Janeiro: Guanabara Koogan, 1986. 2000 p.

HILDEBRAND, M.; GOSLOW, J. R. G. E. Análise da estrutura dos vertebrados. 2 ed. São Paulo: Atheneu, 2006. 638 p.

HOFFER, R. E.; MACCOY, D. M.; QUICK, C. B. Management of acquired achalasia in dogs. Journal of the American Veterinary Medical Association, Schaumburg, v. 175, n. 8, p. 814-817, 1979.

INTERNATIONAL COMMITTEE ON VETERINARY GROSS ANATOMICAL NOMENCLATURE. Nomina anatomica veterinaria. 6 ed. Hannover, Ghent, Rio de Janeiro and Columbia: World Association on Veterinary Anatomist, 2017. 178 p.

LANGER, P. Lactation, weaning period, food quality, and digestive tract differentiations in eutheria. Evolution, New York, v. 57, n. 5, p. 1196-1215, 2003.

MAGAlHÃES, M. S.; FREITAS, M. D. L.; SILVA, N. B. D.; MOURA, C. E. B. D. Morfologia do tubo digestório da tartaruga 
verde (Chelonia mydas). Pesquisa Veterinária Brasileira, Seropédica, v. 30, n. 8, p. 676-684, 2010.

MURRAY, M. J. O esofago. In: REED, S. M.; BAYLY, W. M. (Ed.). Medicina interna equine. Rio de Janeiro: Guanabara Koogan, 1998. p. 524-529.

NAPLES, V. L. Form and function of the masticatory musculature in the tree sloths, Bradypus and Choloepus. Journal of Morphology, Malden, v. 183, n. 1, p. 25-50, 1985.

NASCIUTTI, L. E.; NARCISO, M. S.; LIMA, A. V. P.; GERLY, A. C.; ORIÁ, R. B. Histologia do tubo digestório. In: ORIÁ, R. B.; BRITO, g. a. DE c. (Ed.). Aparelho Digestório: integração básico-clínica. São Paulo: Blucher, 2016. p. 273-314.

NOMINA HISTOLOGICA VETERINÁRIA. IN: INTERNATIONAL COMMITTEE ON VETERINARY GROSS HISTOLOGICAL NOMENCLATURE. Nomina anatomica veterinaria. 6 ed. Hannover, Ghent, Rio de Janeiro and Columbia: World Association on Veterinary Anatomist, 2017. 78 p

PARSONS, T. S.; ROMER, A. S. Anatomia comparada dos vertebrados. 5. ed. São Paulo: Atheneu, 1985. 560 p.

PINHEIRO, S. D. Comportamento alimentar da preguiça comum Bradypus variegatus (Schinz, 1825) (Xernarthra, Bradypodidae) no Parque Centenário de Barra Mansa-RJ. 2006. 119 f. Dissertação (Mestrado em Ciências Biológicas: Comportamento e Biologia Animal) - Universidade Federal de Juiz de Fora, Juiz de Fora. 2006.

PINHEIRO, A. C. O.; LIMA, A. R.; CARVALHO, A. F.; PEREIRA, L. C.; BRANCO, E. Aspectos morfológicos macro e microscópicos do estômago de tamanduá-mirim (Tamandua tetradactyla). Arquivo Brasileiro de Medicina Veterinária e Zootecnia, Belo Horizonte, v. 66, n. 4, p. 1089-1096, 2014.
QUEIROZ, H. L. Preguiças e guaribas, os mamíferos folívoros arborícolas do Mamirauá. Vol. 2. Rio de Janeiro: Sociedade Civil Mamirauá, 1995. 176 p.

ROSS, M. H.; PAWLINA, W. Histología: texto y atlas color con biología celular y molecular. 6. ed. Madrid: Editorial Médica Panamericana, 2012. 864 p.

SAMUELSON, D. A. Tratado de histologia veterinária. Rio de Janeiro: Elsevier, 2007. 544 p.

STINSON, A. W.; CALHOUN, M. L. Aparelho digestivo. In: DELMANN, H. D.; BROWN, E. M. (Ed.). Histologia veterinária. Rio de Janeiro: Guanabara Koogan, 1982. p. 164-211.

TOlOSA, E. M. C.; RODRIGUES, C. J.; BEHMER, O. A.; FREITAS NETO, A. G. Manual de técnicas para histologia: normal e patológica. São Paulo: Edição Manole, 2003. 241 p.

URBANI, B.; BOSQUE, C. Feeding ecology and postural behaviour of the three-toed sloth (Bradypus variegatus flaccidus) in northern Venezuela. Mammalian Biology, Jena, v. 72, n. 6, p. 321-329, 2007.

VELÁSQUEZ, J. C. C.; BEDOYA, S. A. O.; HERNÁNDEZ, V.G. P. Caracterização microscópica das regiões esofágicas de um grupo de Capivaras (Hydrochoerus hydrochaeris) livres no Brasil. CES Medicina Veterinaria y Zootecnia, Medellín, v. 11, n. 2, p. 73-81, 2016.

ZAMITH, A. P. L. Contribuição para o conhecimento da estrutura da mucosa do esôfago dos vertebrados. Anais da Escola Superior de Agricultura Luiz de Queiroz, Piracicaba, v. 9, p. 357-426, 1952 . 